OPEN ACCESS

Edited by:

Izumi Sugihara,

Tokyo Medical and Dental University,

Japan

Reviewed by: Guillermo Gonzalez-Burgos, University of Pittsburgh, USA Angel Nunez, Universidad Autonoma de Madrid Spain

*Correspondence: Toshihiko Momiyama tmomi@jikei.ac.jp

Received: 01 November 2016 Accepted: 28 April 2017 Published: 11 May 2017

Citation:

Momiyama T and Nishijo T (2017) Dopamine and Serotonin-Induced Modulation of GABAergic and Glutamatergic Transmission in the Striatum and Basal Forebrain. Front. Neuroanat. 11:42. doi: 10.3389/fnana.2017.00042

\title{
Dopamine and Serotonin-Induced Modulation of GABAergic and Glutamatergic Transmission in the Striatum and Basal Forebrain
}

\section{Toshihiko Momiyama* and Takuma Nishijo}

Department of Pharmacology, Jikei University School of Medicine, Tokyo, Japan

Catecholamine receptor-mediated modulation of glutamatergic or GABAergic transmission in the striatum as well as basal forebrain (BF) has been intensively studied during these two decades. In the striatum, activation of dopamine (DA) D2 receptors in GABAergic terminals inhibits GABA release onto cholinergic interneurons by selective blockade of $\mathrm{N}$-type calcium channels. In the BF, glutamatergic transmission onto cholinergic projection neurons is inhibited via DA D1-like receptors by selective blockade of $P / Q$-type calcium channels. On the other hand, presynaptic inhibition of the GABA release onto cholinergic neurons mediated by $\mathrm{D} 1$-like receptors or $5-\mathrm{HT}_{1 \mathrm{~B}}$ receptors is independent of calcium influx. In addition, the DA receptor-mediated calcium influx dependent presynaptic inhibition mentioned above decreases with postnatal development, with selective coupling between DA receptors and each subtype of calcium channels being unchanged. Furthermore, the precise origin of these GABAergic or glutamatergic inputs to postsynaptic neurons can be identified by recent optogenetic approaches. Thus, modulatory mechanisms in specific synaptic connections between certain types of neurons in the striatum and BF are being identified.

Keywords: striatum, basal forebrain, synapse, GABA, glutamate

\section{INTRODUCTION}

Nigro-striatal dopaminergic pathway plays important roles in motor control through the interaction between dopamine (DA) and acetylcholine (ACh; Crag, 2006; Pisani et al., 2007). Previous studies have suggested that disorders of the system could be involved in the basal ganglia-related diseases such as Parkinson's disease (for review, Kreitzer and Malenka, 2008). On the other hand, basal forebrain (BF) nuclei are the origin of cholinergic neurons which project to various brain regions containing cortex and hippocampus (Rye et al., 1984), and have been shown to be involved in attention, arousal, learning, memory and sleep-wake states, as well as the related disorder, including dementia and Alzheimer's disease (Coyle et al., 1983; Oyanagi et al., 1989; Zant et al., 2016).

One of the potential neurophysiological events contributing to the striatum- or BF-related control of brain function mentioned above, is synaptic transmission in these brain regions (Calabresi et al., 2007). Presynaptic modulation of excitatory and inhibitory transmitter release in the striatum as well as BF has been intensively studied during these two decades. Especially, recent studies have clarified ionic mechanisms underlying DA- or serotonin receptor-mediated 
presynaptic modulation of glutamate and GABA release in these forebrain regions; modulation coupled to certain subtypes of calcium channels (Momiyama and Koga, 2001; Momiyama and Fukazawa, 2007) or modulation independent of calcium influx (Momiyama and Sim, 1996; Nishijo and Momiyama, 2016) among different synapses. Unique profiles of postnatal developmental changes in these synaptic modulation have also been clarified (Momiyama, 2003, 2010). Furthermore, specific connections between certain types of striatal neurons have been gradually unveiled by optogenetic approaches applied to these brain regions.

This mini review article focuses on the DA- and serotonin receptor-induced modulation of neurotransmitter release through different types of calcium channels as well as in calcium influx-independent manner, in relation to the involvement of different calcium channels in neurotransmitter release in the striatum and BF.

\section{Multiple Types of Calcium Channels Mediate Central Synaptic Transmission}

Central fast synaptic transmission is regulated by multiple types of $\mathrm{Ca}^{2+}$ channels including $\mathrm{N}-, \mathrm{P} / \mathrm{Q}-, \mathrm{R}-$ and other unknown types (Takahashi and Momiyama, 1993; Wheeler et al., 1994). Using selective blockers, previous studied have estimated that the coefficient for the functional relationship between presynaptic $\mathrm{Ca}^{2+}$ concentration and transmitter release is 3 or 4 (Dodge and Rahamimoff, 1967; Augustine and Charlton, 1986; Takahashi, 1992; Takahashi and Momiyama, 1993; Momiyama and Koga, 2001). On the other hand, a recent study has found that, in the GABAergic synaptic transmission onto BF cholinergic neurons, unlike the previous studies (Dodge and Rahamimoff, 1967; Augustine and Charlton, 1986; Takahashi, 1992; Takahashi and Momiyama, 1993; Momiyama and Koga, 2001), the relation between extracellular calcium concentration and transmitter release follows a power of less than 2 instead of 3-4 (Nishijo and Momiyama, 2016), suggesting variable transmission mechanisms, including release probability, number of release sites and localization of each subtype of $\mathrm{Ca}^{2+}$ channels in relation to release sites, among central synapses.

\section{Coupling between Dopamine $D_{2}$ Receptors and $\mathrm{N}$-Type Calcium Channels}

In the rat striatum, GABAergic synaptic transmission onto cholinergic interneurons is inhibited by activation of presynaptic

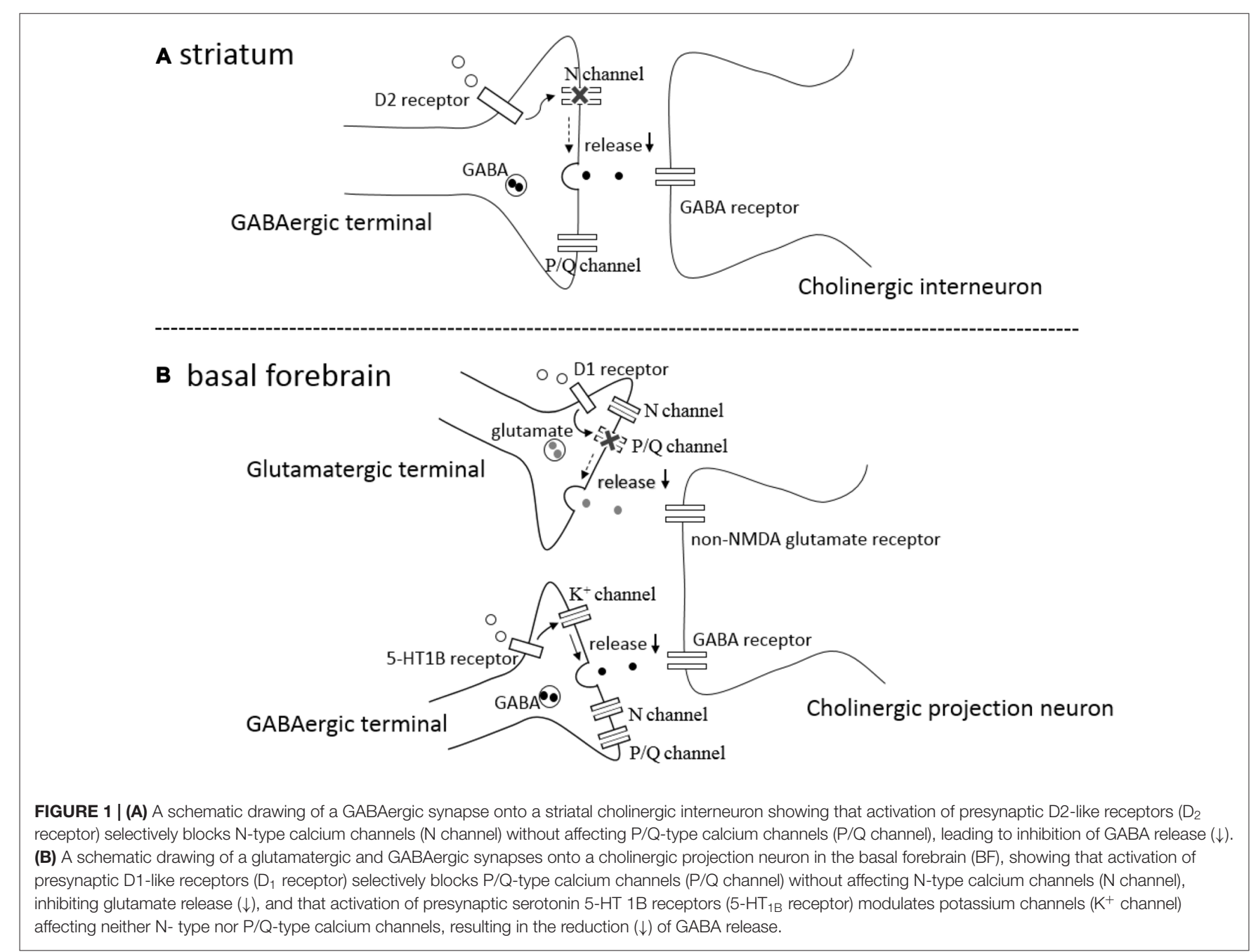


D2-like DA receptors on the GABAergic terminals (Pisani et al., 2000; Momiyama and Koga, 2001). The inhibitory effects induced by agonist activation of D2-like receptors are occluded after blocking $\mathrm{N}$-type $\mathrm{Ca}^{2+}$ channels by $\omega$-conotoxin ( $\omega$-CgTX), whereas the inhibition remained unaffected after blocking P/Qtype $\mathrm{Ca}^{2+}$ channels by $\omega$-Aga-IV-A (Momiyama and Koga, 2001), suggesting that activation of presynaptic D2-like receptors selectively blocks $\mathrm{N}$-type $\mathrm{Ca}^{2+}$ channels, thereby inhibiting GABA release (Figure 1A). The selective coupling is interesting, since the involvement of N-type $\mathrm{Ca}^{2+}$ channels is less than that of $\mathrm{P} / \mathrm{Q}$-type $\mathrm{Ca}^{2+}$ channels in this synapse (Momiyama and Koga, 2001). Among cloned D1-D5 DA receptors, D2-like receptors contains D2, D3 and D4 subtypes. The findings using DA receptor knock-out mice confirmed the involvement of D2 subtype in the D2-like receptor mediated inhibition of GABAergic transmission and selective coupling between D2-like receptors and $\mathrm{N}$-type $\mathrm{Ca}^{2+}$ channels (Sato et al., 2014; Yamada et al., 2016).

\section{Coupling between Dopamine $D_{1}$ Receptors and P/Q-Type Calcium Channels}

In the $\mathrm{BF}$, glutamatergic transmission onto cholinergic neurons is inhibited by activation of presynaptic D1-like DA receptors (Momiyama and Fukazawa, 2007). Unlike the case of D2-like receptor-mediated presynaptic inhibition of GABA release in the striatum mentioned above, D1-like receptor-mediated inhibition is occluded after blocking $\mathrm{P} / \mathrm{Q}$-type $\mathrm{Ca}^{2+}$ channels by $\omega$-Aga-IV-A, whereas the inhibition remained unaffected after blocking $\mathrm{N}$-type $\mathrm{Ca}^{2+}$ channels by $\omega$-CgTX (Momiyama and Fukazawa, 2007), suggesting selective coupling between D1-like DA receptors and P/Q-type $\mathrm{Ca}^{2+}$ channels in the modulation of glutamate release onto cholinergic neurons in the BF (Figure 1B).

\section{Postnatal Developmental Change}

The contribution of $\mathrm{N}$-type $\mathrm{Ca}^{2+}$ channels declines with development and almost diminishes within postnatal 2 weeks in the Calyx of Held (Iwasaki and Takahashi, 1998), whereas the contribution remained unchanged in the spinal cord (Iwasaki et al., 2000). In the striatum of rats or mice, the postnatal developmental change undergoes an intermediate pattern; in the GABAergic transmission onto striatal cholinergic interneurons, N-type $\mathrm{Ca}^{2+}$ channel contribution gradually decline until postnatal 60 days (Momiyama, 2003). In addition, D2-like DA receptor-mediated presynaptic inhibition decreases with age in parallel with the decline in the contribution of $\mathrm{N}$-type $\mathrm{Ca}^{2+}$ channels to the synaptic transmission (Momiyama, 2003; Sato et al., 2014; Yamada et al., 2016; Figures 2A,C).

In the $\mathrm{BF}$ glutamatergic transmission onto cholinergic neurons of the rat, selective coupling between D1-like receptors and $\mathrm{P} / \mathrm{Q}$-type $\mathrm{Ca}^{2+}$ channels mentioned above (Momiyama and Fukazawa, 2007) remains with postnatal development. However, in this glutamatergic synapse, both D1-like receptor-mediated presynaptic inhibition of glutamate release and contribution of $\mathrm{P} / \mathrm{Q}$-type $\mathrm{Ca}^{2+}$ channels to the synaptic transmission increase in parallel (Momiyama, 2010; Figure 2B), while D2-like receptormediated presynaptic inhibition and the $\mathrm{N}$-type $\mathrm{Ca}^{2+}$ channels

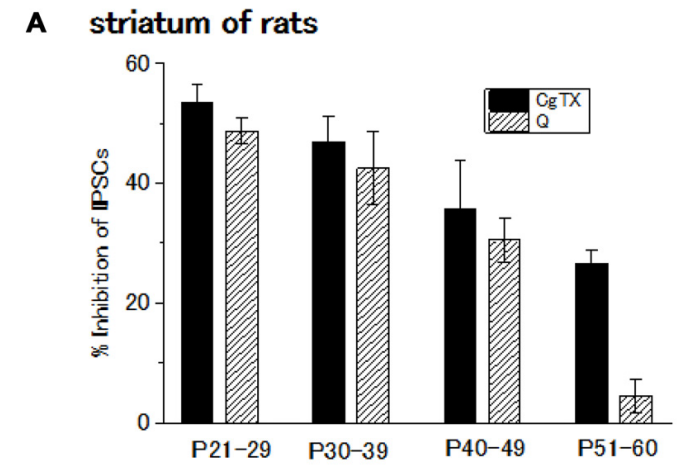

B $\quad$ BF of rats

C striatum of mice
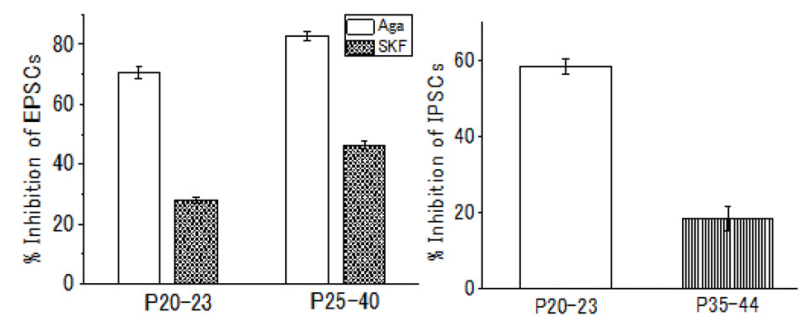

FIGURE 2 | (A) Developmental decrease in the inhibitory effect of $\omega$-conotoxin (CgTX), an N-type $\mathrm{Ca}^{2+}$ channel blocker, or quinpirole (Q), a dopamine (DA) D2-like receptor agonist, on the GABAergic inhibitory postsynaptic currents (IPSCs) evoked in striatal cholinergic interneurons of rats. Each bar shows the mean with SEM derived from 3 to 16 cells. Reproduced from the values published in Momiyama (2003). (B) Developmental increase in the inhibitory effect or SKF81297 (SKF), a D1-like receptor agonist, or $\omega$-agatoxin (Aga), a $\mathrm{P} / \mathrm{Q}$-type $\mathrm{Ca}^{2+}$ channel blocker $\mathrm{Ca}^{2+}$ channel blocker on the glutamatergic excitatory postsynaptic currents (EPSCs) evoked in BF cholinergic neurons of rats. Each bar shows the mean with SEM obtained in 3-36 cells. Reproduced from the values published in Momiyama (2010). (C) Developmental decrease in the inhibitory effect of CgTX on the GABAergic IPSCs evoked in striatal cholinergic interneurons of mice. Each bar shows the mean with SEM derived from 6 to 7 cells. Reproduced from the values published in Sato et al. (2014).

contribution to the synaptic transmission both decrease in the striatum during development (Momiyama, 2003; Sato et al., 2014; Figures 2A,C).

\section{Calcium Influx-Independent Modulation of Transmitter Release}

A recent study has demonstrated that GABAergic synaptic transmission onto cholinergic neurons in the $\mathrm{BF}$ is inhibited by activation of presynaptic $5-\mathrm{HT}_{1 \mathrm{~B}}$ receptors, and that the inhibition remained unchanged after blocking $\mathrm{N}^{-}, \mathrm{P} / \mathrm{Q}-$, or R-type $\mathrm{Ca}^{2+}$ channels by selective blockers of each $\mathrm{Ca}^{2+}$ channel subtype (Nishijo and Momiyama, 2016). Although the modulation might be regulated by other unknown types of $\mathrm{Ca}^{2+}$ channels, the finding could suggest that $5-\mathrm{HT}_{1 \mathrm{~B}}$ receptor mediated presynaptic inhibition of GABA release is independent of $\mathrm{Ca}^{2+}$ channels and/or $\mathrm{Ca}^{2+}$ influx to presynaptic terminals. In addition, $5-\mathrm{HT}_{1 \mathrm{~B}}$ receptor-mediated inhibition was blocked in the presence of $4-\mathrm{AP}$, a potassium channel blocker, suggesting 
the involvement of potassium channel modulation in the inhibition of GABA release (Figure 1B). It remains unknown whether $\mathrm{Ca}^{2+}$-dependent and $\mathrm{Ca}^{2+}$-independent modulation of transmitter release play different roles in these neuronal circuits.

\section{Implications}

Postnatal days 60 is the age between adolescence and young adult in the rat (Kokoshka et al., 2000). Therefore, the developmental change in the contribution of N-type $\mathrm{Ca}^{2+}$ channels to striatal synaptic transmission could be involved in the control of vivid motion or complex behaviors prominent especially in younger ages. These findings also indicate that pharmacological manipulation of N-type $\mathrm{Ca}^{2+}$ channels could be at least one of the therapeutic tools for the age-dependent treatment of basal ganglia-related diseases.

On the other hand, BF cholinergic system has been implicated in attention, motivation or memory (Arendt et al., 1989; Dunnett and Fibiger, 1993; Muir et al., 1994) as well as in the related disorders such as Alzheimer's disease (Price et al., 1986; Mann, 1988; Perry et al., 1993; Gaula and Mesulam, 1994). Therefore, the findings regarding the selective coupling between D1-like receptors and P/Q-type $\mathrm{Ca}^{2+}$ channels in the modulation of $\mathrm{BF}$ glutamatergic transmission suggest possible involvement of P/Q-type $\mathrm{Ca}^{2+}$ channels in these neuropsychiatric functions. Furthermore, a recent finding regarding the involvement of potassium channel modulation in the inhibition of GABA release (Nishijo and Momiyama, 2016) suggests some supplementary role of potassium channels in these functions as well as in the related disorders.

\section{Perspective}

In above-mentioned patch-clamp studies using brain slice preparations of rats or mice, the precise origins of GABAergic or glutamatergic synaptic inputs to striatal or $\mathrm{BF}$ neurons are unidentified. The limitations have been overcome with recent advance in optogenetic technique,

\section{REFERENCES}

Arendt, T., Allen, Y., Marchbanks, R. M., Schugens, M. M., Sinden, J., Lantos, P. L., et al. (1989). Cholinergic system and memory in the rat: effects of chronic ethanol, embryonic basal forebrain brain transplants and excitotoxic lesions of cholinergic basal forebrain projection system. Neuroscience 33, 435-462. doi: 10.1016/0306-4522(89)90397-7

Augustine, G. J., and Charlton, M. P. (1986). Calcium dependance of presynaptic calcium current and post-synaptic response at the squid giant synapse. J. Physiol. 381, 619-640. doi: 10.1113/jphysiol.1986.sp016347

Calabresi, P., Picconi, B., Tozzi, A., and Di Filippo, M. (2007). Dopamine-mediated regulation of corticostriatal synaptic plasticity. Trends Neurosci. 30, 211-219. doi: 10.1016/j.tins.2007.03.001

Castejon, C., Barros-Zulaica, N., and Nuñez, A. (2016). Control of somatosensory cortical processing by thalamic posterior medial nucleus: a new role of thalamus in cortical Function. PLoS One 11:e0148169. doi: 10.1371/journal. pone.0148169

Chuhma, N., Tanaka, K. F., Hen, R., and Rayport, S. (2011). Functional connectome of the striatal medium spiny neuron. J. Neurosci. 31, 1183-1192. doi: 10.1523/JNEUROSCI.3833-10.2011 where certain populations of neurons can be activated by optical stimulation of channelrhodopsin-2 expressed in the neurons. Actually, major origins of GABAergic synaptic inputs onto striatal cholinergic interneurons have been identified to be medium spiny neurons within the striatum (Chuhma et al., 2011). Also, functional synaptic inputs from BF cholinergic neurons to basolateral amygdala neurons have been shown (Unal et al., 2015). Using this technique, input-specific modulation of synaptic transmission as well as selective coupling between receptors and channels will be clarified.

It has been shown that P/Q-type $\mathrm{Ca}^{2+}$ channels are expressed on the axon terminal of parvalbumin (PV)-containing interneurons in the cortex (Castejon et al., 2016). PV-containing GABAergic neurons are also one of the main neuronal populations in the $\mathrm{BF}$, sending GABAergic inputs to cholinergic neurons (Duque et al., 2000; Zaborszky and Duque, 2000). Therefore, PV-containing GABAergic neurons in the BF might also express a certain subtypes of $\mathrm{Ca}^{2+}$ channels, regulating GABA release onto cholinergic neurons. The issues will be also clarified by future studies using optogenetics in combination with ultrastructural technique.

\section{AUTHOR CONTRIBUTIONS}

TN and TM equally contributed the experiments and data analyses in the studies cited in the review article. TN wrote the first draft of the manuscript, and TM revised it in discussion with TN.

\section{FUNDING}

This work was supported by a Grant-in-Aid for Scientific Research from the Ministry of Education, Culture, Sports, Science and Technology of Japan (no. 21500374 and 24500464) to TM.

Coyle, J. T., Price, D. L., and DeLong, M. R. (1983). Alzheimer's disease: a disorder of cortical cholinergic innervation. Science 219, 1184-1190. doi: $10.1126 /$ science. 6338589

Crag, S. J. (2006). Meaningful silences: how dopamine listens to Ach pause. Trends Neurosci. 29, 125-131. doi: 10.1016/j.tins.2006. 01.003

Dodge, F. A., and Rahamimoff, R. (1967). Co-operative action of calcium ions in transmitter release at the neuromuscular junction. J. Physiol. 193, 419-432. doi: 10.1113/jphysiol.1967.sp008367

Dunnett, S. B., and Fibiger, H. C. (1993). Role of forebrain cholinergic systems in learning and memory: relevance to the cognitive deficits of aging and Alzheimer's dementia. Prog. Brain Res. 98, 413-420. doi: 10.1016/s00796123(08)62425-5

Duque, A., Balatoni, B., Detari, L., and Zaborszky, L. (2000). EEG correlation of the discharge properties of identified neurons in the basal forebrain. J. Neurophysiol. 84, 1627-1635.

Gaula, C., and Mesulam, M. M. (1994). "Cholinergic systems and related neuropathological predilection patterns in Alzheimer's disease," in Alzheimer's Disease, eds R. D. Terry, B. Katzman and K. L. Bic (New York, NY: Rave Press), 263-291. 
Iwasaki, S., Momiyama, A., Uchitel, O. D., and Takahashi, T. (2000). Developmental changes in calcium channel subtypes mediating central synaptic transmission. J. Neurosci. 20, 59-65.

Iwasaki, S., and Takahashi, T. (1998). Developmental changes in calcium channel types mediating synaptic transmission in rat auditory brainstem. J. Physiol. 509, 419-423. doi: 10.1111/j.1469-7793.1998.419bn.x

Kokoshka, J. M., Fleckenstein, A. E., Wilkins, D. G., and Hanson, G. R. (2000). Age-dependent differential responses of monoaminergic systems to high doses of methamphetamine. J. Neurochem. 75, 2095-2102. doi: 10.1046/j.1471-4159. 2000.0752095.x

Kreitzer, A. C., and Malenka, R. C. (2008). Striatal plasticity and basal ganglia circuit function. Neuron 60, 543-554. doi: 10.1016/j.neuron.2008. 11.005

Mann, D. M. A. (1988). "Neuropathological and neurochemical aspects of Alzheimer's disease," in Handbook of Psychopharmacology (Vol. 22), eds S. D. Iversen, L. L. Iversen and S. H. Snyder (New York, NY: Plenum Press), 1-56.

Momiyama, T. (2003). Parallel decrease in $\omega$-conotoxin-sensitive transmission and dopamine-induced inhibition at the striatal synapse of developing rats. J. Physiol. 546, 483-490. doi: 10.1113/jphysiol.2002.031773

Momiyama, T. (2010). Developmental increase in D1-like dopamine receptormediated inhibition of glutamatergic transmission through P/Q-type channel regulation in the basal forebrain of rats. Eur. J. Neurosci. 32, 579-590. doi: 10.1111/j.1460-9568.2010.07306.x

Momiyama, T., and Fukazawa, Y. (2007). D1-like dopamine receptors selectively block P/Q-type calcium channels to reduce glutamate release onto cholinergic basal forebrain neurones of immature rats. J. Physiol. 580, 103-117. doi: 10.1113/jphysiol.2006.125724

Momiyama, T., and Koga, E. (2001). Dopamine $\mathrm{D}_{2}$-like receptors selectively block $\mathrm{N}$-type $\mathrm{Ca}^{2+}$ channels to reduce GABA release onto rat striatal cholinergic interneurones. J. Physiol. 533, 479-492. doi: 10.1111/j.1469-7793.2001. 0479a.x

Momiyama, T., and Sim, J. A. (1996). Modulation of inhibitory transmission by dopamine in rat basal forebrain nuclei: activation of presynaptic D1-like dopaminergic receptors. J. Neurosci. 16, 7505-7512.

Muir, J. L., Everitt, B. J., and Robbins, T. W. (1994). AMPA-induced excitotoxic lesions of the basal forebrain: a significant role for the cortical cholinergic system in attentional function. J. Neurosci. 14, 2313-2326.

Nishijo, T., and Momiyama, T. (2016). Serotonin 5-HT1B receptor-mediated calcium influx-independent presynaptic inhibition of GABA release onto rat basal forebrain cholinergic neurons. Eur. J. Neurosci. 44, 1747-1760. doi: 10.1111/ejn.13273

Oyanagi, K., Takahashi, H., Wakabayashi, K., and Ikura, F. (1989). Correlative decrease of large neurons in the neostriatum and basal nucleus of Meynert in Alzheimer's disease. Brain Res. 504, 354-357. doi: 10.1016/00068993(89)91384-x

Perry, E. K., Irving, D., Kerwin, J. M., McKeith, I. G., Thomson, P., Collerton, D., et al. (1993). Cholinergic transmitter neurotrophic activities in Lewy body dementia: similarity to Parkinson's and distinction from Alzheimer's disease. Alzheimer Dis. Assoc. Disord. 7, 69-72. doi: 10.1097/00002093-19930702000002
Pisani, A., Bernardi, G., Ding, J., and Surmeier, D. J. (2007). Re-emergence of striatal cholinergic interneurons in movement disorders. Trends Neurosci. 30, 545-553. doi: 10.1016/j.tins.2007.07.008

Pisani, A., Bonsi, P., Centonze, D., Calabresi, P., and Bernaidi, G. (2000). Activation of D2-like dopamine receptors reduces synaptic inputs to striatal cholinergic interneurons. J. Neurosci. 20:RC69.

Price, D. L., Whitehouse, P. J., and Struble, R. G. (1986). Cellular pathology in Alzheimer's and Parkinson's disease. Trends Neurosci. 9, 29-33. doi: 10.1016/0166-2236(86)90011-1

Rye, D. B., Wainer, B. H., Mesulum, M.-M., Mufson, E. J., and Saper, C. B. (1984). Cortical projections arising from the basal forebrain: a study of cholinergic and noncholinergic components employing retrograde tracing and immunohistochemical localization of choline acetyltransferase. Neuroscience 13, 627-643. doi: 10.1016/0306-4522(84)90083-6

Sato, A., Sasaoka, T., Nishijo, T., and Momiyama, T. (2014). GABAergic synaptic transmission onto striatal cholinergic interneurons ion dopamine D2 receptor knock-out mice. Neuroscience 263, 138-147. doi: 10.1016/j.neuroscience.2014. 01.010

Takahashi, T. (1992). The minimal inhibitory synaptic currents evoked in neonatal rat motoneurones. J. Physiol. 450, 593-611. doi: 10.1113/jphysiol. 1992.sp019145

Takahashi, T., and Momiyama, A. (1993). Different types of calcium channels mediate central synaptic transmission. Nature 366, 156-158. doi: $10.1038 / 366156 \mathrm{a} 0$

Unal, C. T., Pare, D., and Zaborszky, L. (2015). Impact of basal forebrain cholinergic inputs on basolateral amygdala neurons. J. Neurosci. 35, 853-863. doi: 10.1523/JNEUROSCI.2706-14.2015

Wheeler, D. B., Randall, A., and Tsien, R. W. (1994). Roles of N-type and Q-type $\mathrm{Ca}^{2+}$ channels in supporting hippocampal synaptic transmission. Science 264, 107-111. doi: 10.1126/science.7832825

Yamada, K., Takahashi, S., Karube, F., Fujiyama, F., Kobayashi, K., Nishi, A., et al. (2016). Neuronal circuits and physiological roles of the basal ganglia in terms of transmitters, receptors and related disorders. J. Physiol. Sci. 66, 435-446. doi: 10.1007/s12576-016-0445-4

Zaborszky, L., and Duque, A. (2000). Local synaptic connections of basal forebrain neurons. Behav. Brain Res. 115, 143-158. doi: 10.1016/s0166-4328(00)00255-2

Zant, J. C., Kim, T., Prokai, L., Szarka, S., McNally, J., McKenna, J. T., et al. (2016). Cholinergic neurons in the basal forebrain promote wakefulness by actions on neighboring non-cholinergic neurons: an opto-dialysis study. J. Neurosci. 36, 20547-22067. doi: 10.1523/JNEUROSCI.3318-15.2016

Conflict of Interest Statement: The authors declare that the research was conducted in the absence of any commercial or financial relationships that could be construed as a potential conflict of interest.

Copyright (c) 2017 Momiyama and Nishijo. This is an open-access article distributed under the terms of the Creative Commons Attribution License (CC BY). The use, distribution or reproduction in other forums is permitted, provided the original author(s) or licensor are credited and that the original publication in this journal is cited, in accordance with accepted academic practice. No use, distribution or reproduction is permitted which does not comply with these terms. 